\title{
AVALIAÇÃO DA ASSISTEENCIA PRESTADA PELO ESTUDANTE DE ENFERMAGEM EM UM HOSPITAL GERAL DO INAMPS NA CIDADE DO RECIFE - OPINIĀO DOS PACIENTES
}

\author{
Lenes Clécia Saraiva Lins ${ }^{1}$, Maria da Penha Carlos de Sá 2
}
LINS, L.C.S. \& SÁ, M.P.C. de. Avaliação da assistência pres- tada pelo estudante de enfermagem em um hospital geral do INAMPS na cidade do Recife; opinião dos pacientes. Rev. Bras. Enf., Brasília, 39(2/3): 38-45, abr./set., 1986.

\begin{abstract}
RESUMO. Considerando as dificuldades existentes na utilização de Hospitais do INAMPS, como campo de estágio, as autoras desenvolveram esta pesquisa objetivando avaliar a assistência prestada pelos estudantes, a aceitação da mesma pelos pacientes, confrontando com a opinião da direção dos Hospitais sobre o assunto. $\mathrm{O}$ estudo abrange o trabalho realizado pelas estudantes de enfermagem junto a 41 pacientes cumprindo o estágio curricular de Introdução à Enfermagem II. Conclui que o paciente previdenciário aceita e até prefere a assistência prestada pelo estudante, identifica uma assistência sistematizada e metodológica e sugere que haja continuidade de estágios que são proveitosos tanto para o paciente como para a Instituição.
\end{abstract}

ABSTRACT. Considering the difficulties in the utilization of INAMPS Hospital how training field, the autors developed this research to evaluate the nursing care gived by the nursing students through the patients 'and doctors' opinion. The study related the work developed by the nursing students with the patients int he Nursing Introduction II discipline. The main conclusion of this work is that the social welfare institution patient prefer the nursing care gived by the nursing student because is a sistematic and methodological assistence and suggest that the training will be continue by their importance to the patient and institution.

\section{INTRODUÇÃO}

É através do processo de comunicação que as idéias, pensamentos e ações são permutadas; é através desse processo que a interação é estabelecida, favorecendo conseqüentemente o conviver e o lidar com pessoas. É na convivência com o homem sadio ou doente, que o enfermeiro identifica suas reais necessidades, as quais são externalizadas através dos componentes biológico, psicológico, social e espiritual. Para que esse processo seja efetivado, é indispensável ao enfermeiro conhecer o cliente/paciente dentro de sua cultura e com seus valores; há necessidade de conhecer-se também a si mesmo. Somente frente a esses aspectos a prática profissional é alicerçada, constituindo portanto elementos básicos na formação do aluno de enfermagem que procura na sua formação acadêmica o saber da enfermagem (conhecimento) corporifica- do em um nível técnico (representado pelos instrumentos e condutas) e nas relações sociais específicas para atender às necessidades humanas (ALMEIDA ${ }^{1}$ ).

As informações e/ou ensinamentos que são emitidos ao aluno de enfermagem no sistema formal são fortalecidos no campo de prática, o qual é desenvolvido na comunidade, visando a aplicação de medidas preventivas, e nos hospitais, onde se desenvolve basicamente a assistência curativa. $O$ assistir em enfermagem envolve a prestação de cuidados, objetivando o atendimento do homem nas suas necessidades básicas, e, neste atendimento, o ser humano deve ser visualizado como um todo indivisível. É nessa linha de ação que o aluno é orientado. A ele é ensinado que o agir envolve fundamentação científica, que cada ação implica em reflexão, que esta reflexão conduz à manutenção ou a uma nova ação, caracterizando portanto uma forma metodológica da assistência através

\footnotetext{
1. Professor Assistente do Departamento de Enfermagem da Universidade Federal de Pernambuco. Coordenadora da Comissão de Divulgação da ABEn.

2. Prof essor Auxiliar de Ensino do Departamento de Enfermagem da Universidade Federal de Pernambuco.
} 
de um processo sistêmico. É dentro desse processo que se estabelece o relacionamento interdependente aluno/paciente firmando assim a relação de ajuda na qual a confiança é estabelecida. Isso implica que as ações de enfermagem devem ser planejadas com o paciente, sendo aconselhável a participação da família, a qual deverá ser envolvida na assistência.

A co-participação favorece a exeqüibilidade do processo pelo educando que procura sistematizar suas ações objetivando atender as necessidades do paciente que fica sob sua responsabilidade. Este aspecto se reveste de dinamismo, trazendo, entre outras, modificações no comportamento do educando, que incorpora lentamente compromisso e comprometimento com a profissão, envolvimento e responsabilidade no assistir, trazendo portanto mudanças no seu comportamento, o que significa que ocorreu a aprendizagem. É essa a ciência da enfermagem tão bem caracterizada por PAULA 13 quando afirma que "enfermagem é a ciência do cuidar" e por HORTA apud PAULA13 quando diz que o enfermeiro "é gente que cuida da gente".

\section{PROBLEMA E JUSTIFICATIVA DO ESTUDO}

Já se caracterizou que cuidar envolve agentes da ação, recipiente ou receptor da ação, contexto e planejamento.

Sabe-se sobre alguns dos aspectos que compete ao sistema educacional formal, na orientação do aluno de enfermagem, para atuar na prática. Resta estabelecer a responsabilidade e/ou o cometimento desse mesmo sistema para com os profissionais de campo (enfermeiros assistenciais) e, conseqüentemente, para com a instituição prestadora de assistência, e a contribuição desta na formação do futuro profissional de enfermagem, bem como o seu compromisso para a comunidade que começa a perceber seus direitos na conquista da saúde, exigindo uma assistência qualificada para a sua preservação. É baseado nestes anseios que se busca solução, encontrando-se respostas que são alicerçadas no Programa de Interação Docente-Assistencial (IDA) fruto do trabalho conjunto do MEC/SESU/CCS e surgido em 1979 com a renovação do acordo entre OPS/MEC/MPAS. "O seu conceito poderia resumir-se em união de esforços em um processo de crescente articulação entre Instituições de Educação e de Serviços de Saúde adequados as reais necessidades da população, a produção de conhecimentos e a formação de recursos humanos necessários" (BRASIL. Ministério da Educação e Cultura ${ }^{4}$ ). Vislumbra-se claramente nesse conceito a recomendação que deve pairar entre os serviços de formação e os de prestação de assistência, os quais devem interagir continuamente, de modo a contribuir de forma bilateral no alcance dos objetivos pertinentes às Instituições. Assim é que o órgão de formação abre suas portas para receber os profissionais de serviços no engajamento desses, em cursos de Atualização, Especialização, Mestrado e Doutorado, contribuindo assim de forma marcante para a educação continuada desses profissionais. Esforços têm sido realizados para que os enfermeiros assistenciais realizem pesquisas e trabalhos no seu campo de ação, recebendo contínuo estímulo e orientação do corpo docente da universidade. Têm sido realizadas orientações para implantação e reestruturação dos serviços e tem havido participação em atividades educativas às várias categorias de enfermagem nas instituições de assistência. Há também casos em que por solicitação de dirigentes das instituições assistenciais, a Universidade permite ao docente reservar parte de sua carga horária para atender as necessidades da Instituição solicitante; nessas, o docente desenvolve além das atividades citadas anteriormente, as ligadas à assistência, assessoria e ao planejamento. Todo este cenário mostra a preocupação que tem o setor educacional, representado pelos docentes, com a melhoria das instituições assistenciais, com o crescimento dos profissionais de saúde nela inseridos e com a comunidade, que é beneficiada por uma assistência mais qualificada. E as instituições de serviço? Como tem sido o desempenho e o posicionamento dos profissionais de enfermagem e dos dirigentes dessas instituições na formação do aluno de enfermagem que utiliza seus campos para fortalecer os conhecimentos teóricos adquiridos intra-muros da universidade? É tão variado o tipo de receptividade e/ou da aceitação docente/discente, nas instituições prestadoras de assistência, que as respostas às questões formuladas dependerão do estabelecimento (empresa) e do momento vivido. Assim é que em algumas (quer sejam da rede oficial do Estado, da Universidade ou do INAMPS) encontra-se o apoio dos dirigentes e de parte da equipe de enfermagem, que fica entre a aceitação, rejeição e a indiferença. Em outras, sente-se que a equipe de enfermagem é totalmente solidária, coesa, mostrando-se participativa já que acompanha todo o processo educativo relacionado às atividades docente/discente no serviço. Esse inter-relacionamento foi observado na Instituição onde se desenvolveu o estudo, cujo intercâmbio interinstitucional e dinâmica intra-institucional vem sendo alimentados há alguns anos. Entretanto, tem-se observado que algumas das direções dos hospitais do INAMPS têm colocado obstáculos ao ensino prático dos estudantes de enfermagem apresentando como justificativas:

a) o paciente previdenciário não deve ser manipulado por estudantes da universidade. $\mathrm{O}$ Hospital das Clínicas da UFPE deve ser o único campo de prática para os alunos, pois os doentes ali hospitalizados já são preparados para a aceitação do educando;

b) os pacientes previdenciários não querem ser atendidos por estudantes de enfermagem;

c) à direção se permite o direito de decidir sobre a permanência de estagiários, não tendo sido suficientes os argumentos do corpo clínico e de enfermagem para remover as barreiras estabelecidas.

\section{OBJETIVOS:}

- Verificar se os pacientes distinguem o estudante de outros profissionais dentro da equipe de enfermagem;

- Avaliar como os pacientes recebem ou aceitam a assistência prestada pelos estudantes de enfermagem;

- Conf rontar a opinião emitida pelos pacientes 
com a da direção do hospital geral do INAMPS sobre a aceitação e/ou rejeição dos pacientes acerca da assistência prestada pelo estudante de enfermagem.

\section{REVISÃO DA LITERATURA}

O Departamento de Enfermagem da UFPE, no intuito de proporcionar ao discente uma visão ampla sobre a assistência prestada ao cliente/paciente nos diversos serviços do Estado, tem utilizado como campo de prática os postos de saúde e hospitais do interior (salientando aqui o internato rural) e da área metropolitana. Assim é que a rede oficial do Estado, os hospitais universitários, os estabelecimentos próprios do INAMPS (PAMs e hospitais) e alguns serviços da rede particular têm sido utilizados como campo de prática para o aluno de enfermagem que procura inserir suas atividades nos três níveis de assistência. Além de levar ao aluno uma visão global da assistência, é preocupação do Departamento agilitar sobre o Programa de Integração Ensino/Serviço (Integração Docente Assistencial) na UFPE. Entre os vários objetivos estabelecidos para esse programa, cita-se a seguir os considerados de maior abrangência:

- "Ampliar as oportunidades de Prática de Ensino e de Pesquisa de forma a contribuir para a adequação de programas docentes e discentes da universidade às necessidades da região.

- Melhorar a qualidade do ensino, através da prática de treinamento multiprofissional supervisionado, em instituições da rede de serviços de saúde da região.

- Implantar projetos inovadores de caráter extra mural que permitam a integração entre as diferentes profissões".

$\mathrm{O}$ art. 30 desse programa fala da constituição de uma comissão para acompanhar todo o processo IDA, a qual conta com representantes do INAMPS, Secretaria de Saúde, CCS-UFPE (BEZERRA ${ }^{3}$ ).

Para respaldar o propósito do Departamento de Enfermagem da UFPE na consolidação do programa IDA, convém salientar que o Plano Decenal de Saúde para as Américas (1971-1980) recomenda à enfermagem criar condições e melhorar a qualidade da prestação de assistência através da integração entre ensino e os serviços de enfermagem (FERNANDES \& LEITE10). Frente a esta recomendação e com a preocupação de levar uma assistência mais adequada à população previdenciária, o serviço de enfermagem do hospital onde a pesquisa foi realizada e docentes do Departamento de Enfermagem agilitaram o intercâmbio que já havia sido iniciado há 16 anos, porém que acontecia dicotomizado. A partir de 1980, um dos autores do estudo, ex-assistencial daquela instituição hospitalar, passou a utilizar sistematicamente o campo com alunos de Introdução à Enfermagem 2, quando o processo de IDA foi dinamizado passando realmente a ser efetivo. Isso permitiu ao docente participar de várias atividades do Serviço de Enfermagem, prestando assessoria em vários assuntos chegando a plenejar e implantar unidades. Reforçando esta linha de ação, cita-se ARAÚJO2 quando afirma que "as unidades do INAMPS vêm sendo utilizadas como campo de es- tágio para os estudantes de enfermagem nos diversos níveis". Ressalta-se que para educar não deve existir fronteira, muros, espaços, limites. A educação deve ser livre e deve estar ao dispor de todos, bem como a saúde. FURTER apud VIEIRA15 diz que "a educação deve ser simultânea, considerar o homem no meio sócio-profissional onde aparece como produtor e colaborador do desenvolvimento; no meio sócio-político onde age como utilizador e participante ativo do processo de transformação da sociedade; e no meio sócio-cultural em que age como criador e inovador, permitindo-lhe a auto expressão no processo de modernização". E VIEIRA 15 continua citando que "é tarefa do enfermeiro participar do processo educativo dos diversos elementos da equipe de saúde, quer seja a nível superior, 29 grau ou elementar". FERNANDES \& LEITE10, em trabalho de pesquisa sobre a opinião dos enfermeiros acerca dos estudantes, encontraram como vantagens dessa atividade, a melhoria da clínica, melhor entrosamento do aluno/funcionário, dinamização do serviço, serviço executado com mais técnica e intercâmbio teoria e prática. Convém também analisar os benefícios oriundos do relacionamento entre o binômio enfermeiro/aluno. O enfermeiro participa com sua experiência no aprendizado do educando e este, funcionando como mola propulsora, força de certa forma o assistencial a utilizar seus conhecimentos teóricos nas respostas emitidas ao aluno. CIETTO \& PEREIRA ${ }^{7}$ defendem esta afirmativa, colocando que "doutrinariamente, já não subsiste dúvidas a respeito de uma das mais importantes funções do enfermeiro, ou seja, o seu dever de contribuir e participar de forma responsável no programa educativo de qualquer estudante que esteja adquirindo experiência clínica em sua unidade de trabalho". Portanto, a presença do aluno impulsiona as ações e contribui para mudança, e essa mudança é mais expressiva na assistência que ele presta de forma personalizada e humanizada, vez que utiliza, no desenvolvimento de suas atividades, o Processo de Enfermagem. Este processo representa a relação de ajuda que ocorre entre quem presta a assistência e a pessoa que é assistida (CARVALHO ${ }^{5}$ ). Tem sido difícil a sua implantação nos serviços e somente com a presença do aluno se tem conseguido bons resultados. São inúmeros os benefícios da sua existência nas instituições, uma vez que facilita o processo de auditagem, a sistematização das ações de enfermagem e a visão do paciente de forma holística, estabelecendo-se uma avaliação contínua de todo processo. VIEIRA15 considera que "a avaliação da prática permite a identificação de aspectos positivos e negativos, garantindo o reforço do primeiro e a superação do segundo". Essa avaliação deve ser realizada em todos os ângulos e ser abrangente de modoque se possa intervir com soluções em todas as áreas da assistência. Desta forma se pode ter uma visão ampla de como se encontram os profissionais e qual a sua posição dentro do serviço.

E partindo deste ponto se questiona: qual a posição da direção dos hospitais frente a presença de estudantes da área de saúde? Em que difere a presença do estudante de medicina em relação aos demais estudantes sobretudo o de enfermagem? 
Respondendo a estas questões, OGUISSO11 afirma que o INAMPS se assemelha a outras instituições no que concerne à situação do médico e dos demais prof issionais, afirmando que, nas instituições de assistência à saúde, há dominância das ações médicas sobre as demais ações de outros profissionais de saúde. Ao médico é atribuído maior prestígio, maior importância nas ações assistenciais, estabelecendo-se assim uma subvalorização na formação e utilização das outras categorias profissionais, especialmente a de enfermagem. Reforçando esse pensamento, SANTOS apud FERNANDES9 afirma que "o médico no processo de trabalho encontra-se posicionado no vértice de uma pirâmide de autoridade técnica... É o único que tem nas mãos o doente e sente-se o mais importante entre os demais profissionais. É gratificante porém pensar que os serviços de saúde mudarão e que os mesmos não terão o monopólio dos médicos, e sim, que a participação coletiva de todos os profissionais seja uma realidade". É nessa moldura que se quer formar o enfermeiro, onde as decisões de uma só pessoa não tenham repercussão mesmo que esta pessoa esteja gerenciando uma empresa. A realidade é como cita GALBRAITH apud OLIVEIRA 12 "vivemos na idade da incerteza e devemos aprender a tolerar ambiguidades que se estendem a todos os seguimentos sociais". E bem caracteriza FARAON9 quando afirma "ser por formação e por profissão, adepta da corrente de que a base de tudo se encontra no que chamamos de mentalidade e que podemos também denominar de movimento intelectual de estado psicológico". Acredita a mesma autora que, para implementar os princípios, conceitos, conteúdos de forma permanente, seja necessária a mudança de mentalidade ou a criação de uma nova mentalidade. Isso só é conseguido através da educação, pois só ela transforma a mente das pessoas. Toda essa proposta de mudança só pode ser conseguida nos serviços com a implementação de ações conjuntas, onde o ensino/serviço trabalhem de forma integralizada. Porém, ações de dirigentes como a observada no estudo faz pensar no que foi dito por PINHEIRO apud OLIVEIRA12 "há disritmia entre o ensino e a prática". É lamentável que se tenha de ensinar ao aluno aquilo que nem sempre é encontrado na prática. Fala-se para ele em equipe multiprofissional, de inter-relacionamento entre os membros da equipe, de instituições com objetivos voltados para o paciente e não para atender às necessidades pessoais de cada um; de dirigentes escolhidos por capacidade e por obediência a certos critérios (relacionamento, imparcialidade, competência, espírito aberto a críticas, visão voltada para os aspectos sociais onde o educativo está inserido...) e não por indicação, onde a manipulação política é uma realidade.

Daí porque há necessidade de se relatar para o aluno o cenário real dos campos de prática, conduzindo-os à reflexão sobre os aspectos positivos e negativos encontrados nos serviços; esta reflexão lhe trará maturidade profissional e, conseqüentemente, suporte para enfrentar e lutar quando frente a obstáculos, evitando sempre a fuga como defesa. As palavras de OGUISSO 11 citadas a seguir, servem para transmitir fé e força para os que fazem a enfermagem; mostra a autora que é questão de tempo quando afirma que "dia virá ém que a enfermagem pela dignidade e respeito que reveste seu objeto central, o HOMEM, necessita estar estruturada de modo a poder cumprir com eficiência as funções que lhe são próprias" e, complementando, desfrutar dos direitos que lhe são inerentes.

\section{DEFINIÇÃO OPERACIONAL DE TERMOS}

- cliente/paciente - objeto das ações dos profissionais de saúde.

- sistema formal - instituição representada pela universidade responsável pela graduação e pós-graduação do aluno.

- campo de prática, contexto - local onde as ações do aluno se processam, representado por Instituições e/ou comunidade.

- agente de ação - enfermeiros, estudantes e outros membros da equipe de saúde.

- receptor da ação - cliente, paciente, família e/ou comunidade.

- planejamento - plano de assistência elaborado com e para o paciente.

- necessidades b́ásicas - conjunto de exigências indispensáveis à sobrevivência do ser humano.

- relacionamento interdependente - interação entre os indivíduos cujas atividades estão interligadas entre si, com um objetivo único.

- processo de enfermagem - conjunto de ações organizadas de enfermagem que incluem a identificação dos problemas e/ou necessidades, execução e avaliação dos resultados obtidos.

\section{METODOLOGIA}

O estudo é exploratório e teve como objetivo avaliar a assistência prestada pelo estudante de enfermagem.

\section{Universo e Amostra}

O universo deste estudo foi constituído por pacientes internados nas Clínicas Médica e Cirúrgica de um hospital geral do INAMPS na cidade do Recife, PE. A amostragem foi constituída por pacientes que recebiam cuidados diretos do estudante de enfermagem, num total de 41 pacientes. Para que a seleção fosse realizada, obedeceu-se aos seguintes critérios:

- a permanência do aluno junto ao paciente não deveria ser inferior a 5 dias, justificando-se que somente após esse espaço de tempo é que o paciente teria condiçôes de emitir qualquer opinião sobre os cuidados que recebia;

- foram excluídos do estudo dos doentes com perturbação do nível de consciência, os que apresentavam taxas bioquímicas elevadas, que os impossibilitariam de se expressar normalmente, os pacientes com distúrbios mentais e os com arteriosclerose.

$\mathrm{O}$ instrumento de medida constou de um questionário composto de 13 perguntas sendo 7 em questões fechadas, 3 em questões abertas e 3 em questões mistas. Precedeu as questões uma parte correspondente à identificação pessoal do paciente, a qual constou 
da identificação pessoal do paciente, grau de instrução, procedência e clínica de internamento. As 4 primeiras questões visaram obter, do respondente informações sobre sua experiência com outros sistemas de saúde, suas expectativas sobre a instituição em que se encontrava, bem como averiguar se o paciente recebeu orientação sobre o hospital e a clínica por ocasião de sua admissão no serviço e quem foi o responsável pela orientação. As 5a e 6a questões tinham como finalidade obter do paciente informações sobre a clínica, ressaltando a assistência que recebia em cada horário. As seis questões que se seguiram estavam relacionadas com o desempenho do aluno (sua identificação dentro da equipe de enfermagem, qualificação da assistência recebida pelo paciente e como o paciente se sentia quando atendido pelo aluno). A 13a questão visava obter do doente opiniões pessoais sobre o aluno e sobre o serviço. Ressalta-se que o instrumento foi organizado de uma forma simples e elementar, considerando o nível educacional da clientela.

Para aplicação do questionário, foi emitida à chefia do serviço de enfermagem uma solicitação, anexando à mesma uma cópia do questionário, e pedia-se à mesma chefia que estendesse o pedido à $\mathrm{Di}$ visão Médica. A solicitação foi acatada, entretanto, estabelecia o Diretor da Divisão Médica que a aplicação do instrumento fosse realizada somente por um dos autores do estudo (ex-funcionário do Serviço).

Assim o pesquisador, seguindo os critérios determinados no estudo, passou a entrevistar os pacientes durante 10 a 15 minutos, tendo antes lhes explicado a finalidade da pesquisa. Essa etapa foi realizada durante o estágio dos alunos do 49 período da disciplina Introdução à Enfermagem 2.

$\mathrm{O}$ período do estágio abrangeu os meses de janeiro (15 dias) e fevereiro (15 dias) de 1985, totalizando 30 dias de atividades práticas em hospitais. O hơrário estabelecido para a prática foi de 7 às 13 horas. A aplicação do instrumento foi iniciada a partir da 2 a semana de prática, pois a primeira correspondeu ao período de adaptação do aluno ao serviço.

\section{ANÁLISE E DISCUSSÃO DOS DADOS}

Como já se configurou no estudo, a aplicação do instrumento foi realizada apenas por um dos pesquisadores, considerando a exigência da direção da instituição. $O$ ideal seria que o questionário fosse aplicado por elementos estranhos à clínica e após a alta do paciente, pois este sentir-se-ia menos constrangido em emitir respostas e/ou informações. Mas, frente à determinação da direção, procurou o autor usar de imparcialidade durante as entrevistas para que o paciente fosse coerente nas suas respostas.

Os resultados do estudo mostraram que 18 $(43,90 \%)$ dos 41 pacientes pertenciam ao sexo masculino e $23(56,10)$ eram do sexo feminino, distribuídos na clínica cirúrgica $25(60,89 \%)$ e $16(39,02 \%)$ na clínica médica.

Houve predominância da faixa etária de 40 a 49 anos com maior percentual $(9-21,95 \%)$ na clíni- ca médica e 5-12 (19\%) na clínica cirúrgica. Foram encontrados extremos de faixa etária com idade mínima entre 10 e 19 anos sendo que $1(2,43 \%)$ era paciente da clínica médica e $4(9,75 \%)$ da clínica cirúrgica, e idade máxima de 70 a 80 anos, com $1(2,43 \%)$ na clínica médica.

Quanto ao estado civil observou-se que 18 $(43,90 \%)$ eram casados, $17(41,46 \%)$ eram solteiros, $4(9,76 \%)$ viúvos, e 2 pacientes $(4,88 \%)$ com situação não especificada.

Dos 41 pacientes do estudo, $15(36,58 \%)$ eram da área metropolitana; $18(44,00 \%)$ do agreste; 4 $(9,70 \%)$ de outros estados; $3(7,30 \%)$ da zona da mata e $1(2,42 \%)$ do alto sertão.

No que se refere à experiência com hospitalização, observou-se no estudo que $9(21,95 \%)$ já tinham sido admitidos em instituições de saúde (inclusive em outras clínicas da instituição em foco), enquanto que $32(78,05 \%)$ nunca haviam sido hospitalizados.

Entre os pacientes que relataram experiências anteriores com hospitalização, ao serem indagados quanto às suas expectativas, $4(44,45 \%)$ esperavam bom atendimento pela equipe de saúde; $3(33,33 \%)$ esperavam boa recuperação; $1(11,11 \%)$ bom atendimento por experiência de familiares e $1(11,11 \%)$ considerava que a assistência recebida ultrapassava suas expectativas.

Dos $32(78,05 \%)$ que nunca foram hospitalizados $24(75,00 \%)$ consideraram a instituição em análise boa em todos os aspectos, $4(12,50 \%)$ consideraram todo hospital bom, $2(6,25)$ disseram que o bom atendimento do hospital é decorrente do pessoal de enfermagem.

A Tabela 1 diz respeito à orientação que os pacientes receberam no serviço quando da sua admissão e revela que $14(34,15 \%)$ receberam orientação ficando o maior percentual $27(65,85 \%)$ sem qualquer esclarecimento sobre a internação.

Dos 14 orientados, observou-se que $5(12,20 \%)$ tiveram sua orientação através da equipe médica, 7 $(17,07 \%)$ foram orientados por estudantes de enfermagem e apenas $1(2,44 \%)$ foi orientado pelo auxiliar de enfermagem e $1(2,44 \%)$ pelo assistente social; não foram encontrados dados que evidenciassem a participação do enfermeiro no processo de admissão (V. Tabela 2).

TABELA 1 - Orientação recebida pelos pacientes da admissão

\begin{tabular}{c|c|c}
\hline RECEBEU ORIENTAÇÃO & $\mathrm{F}$ & $\%$ \\
\hline Sim & 14 & 34,15 \\
Não & 27 & 65,85 \\
\hline TOTAL & 41 & 100,00 \\
\hline
\end{tabular}

Questionados sobre a assistência recebida na instituição, dos 41 pacientes, $27(65,85 \%)$ afirmaram ser excelente enquanto $14(34,15 \%)$ consideraram boa a assistência.

Investigados acerca da assistência recebida nos diferentes turnos de trabalho (manhã, tarde e noite), observou-se que $12(29,27 \%)$ afirmaram existir dife- 
TABELA 2 - Relação de Pessoas que orientaram os pacientes no momento da admissão

\begin{tabular}{l|c|c}
\hline \multicolumn{1}{c|}{ PESSOAS } & F & $\%$ \\
\hline Médico & 5 & 12,20 \\
Enfermeiro & - & - \\
Estudante de Enfermagem & 7 & 17,07 \\
Auxiliares & 1 & 2,44 \\
Assistente social & 1 & 2,44 \\
\hline \multicolumn{1}{c|}{ TOTAL } & 14 & 34,15 \\
\hline
\end{tabular}

rença enquanto $29(70,73 \%)$ negaram diferença. Os que referiram diferenças nos mais diversos turnos relataram que no horário da manhã a assistência é melhor - $5(12,19 \%), 4(9,76 \%)$ consideraram o horário da manhã melhor pela presença do estudante de enfermagem; $2(4,88 \%)$ acharam a noite o pior horário pela deficiência de pessoal e apenas $1(2,44 \%)$ considerou a noite melhor em função da medicação tranquilizante que recebia.

A Tabela 3 reflete as respostas dos pacientes quanto à identificação que eles fazem do estudante dentro da equipe de enfermagem, ficando caracterizadas na mesma que $40(97,56 \%)$ dos pacientes, sabiam que seus cuidados foram prestados pelo estudante e apenas $1(2,44 \%)$ não fez a identificação da pessoa que o assistia. Esse afirmou que a pessoa que cuidava dele "era tão boa que não percebeu diferença entre o estudante e enfermeiro do setor".

TABELA 3 - Distribuição de respostas dos pacientes quanto à identificação do estudante

\begin{tabular}{c|r|r}
\hline IDENTIFICAÇÃO & F & \multicolumn{1}{|c}{$\%$} \\
\hline Sim & 40 & 97,56 \\
Não & 1 & 2,44 \\
\hline TOTAL & 41 & 100,00 \\
\hline
\end{tabular}

Os $40(97,56 \%)$ pacientes que identificaram o estudante, ao serem investigados sobre a fonte que lhes havia fornecido esta informação, $12(29,26 \%)$ responderam que o próprio estudante fez a sua apresentação, $12(29,26 \%)$ perceberam por si mesmos, $5(12,19 \%)$ foram informados por outros pacientes e $11(26,82 \%)$ foram informados pelo professor. (V. Tabela 4). Percebe-se que novamente a enfermeira não participou do processo de integração entre o aluno e o paciente. Dos $12(29,26 \%)$ que perceberam a presença do aluno por si mesmos, dois relataram que a identificação foi feita baseada no trabalho de equipe desenvolvida pelos alunos.

Ao ser solicitado a emitir opinião sobre o trabalho desenvolvido pelo estudante de enfermagem, $29(70,73)$ classificaram como bom, e $12(29,27 \%)$ como excelente. Chama-se atenção que no instrumento foi omitida a classificação excelente, tendo a mesma surgido na análise dos resultados por resposta própria dos pacientes.

Em relação à diferença que o paciente fez da assistência que recebeu do estudante de enfermagem
TABELA 4 - Relação de Pessoas que informaram aos Pacientes sobre a presença dos estudantes.

\begin{tabular}{l|r|r}
\hline INFORMANTE & F & $\%$ \\
\hline O Professor & 11 & 26,82 \\
O Estudante & 12 & 29,26 \\
Percepção do paciente & 12 & 29,26 \\
Outros pacientes & 5 & 12,19 \\
\hline \multicolumn{1}{c|}{ TOTAL } & 40 & 197,56 \\
\hline
\end{tabular}

e dos funcionários, 29 (70,73\%) pacientes consideraram que houve diferença e $12(29,27 \%)$ negaram haver diferņ̧a. Os $29(70,73 \%)$ que perceberam a diferença, apresentaram como justificativas:

" - o estudante nos fornece melhor cuidados, é mais educado e conversa mais conosco" -17 $(41,46 \%)$.

" - o estudante é mais dedicado e carinhoso" - 5 $(12,20 \%)$.

" - é muito diferente; os funcionários não se incomodam muito conosco, talvez porque já estejam feitos e têm seu emprego garantido".

" - é sem comparação a qualidade da assistência, a estudante é uma santa" - $1(2,44 \%)$.

“ - a estudante imprime tranqüilidade" $-2(2,44 \%$. Os $12(29,27 \%)$ que disseram NÃO, afirmaram "não querer prejudicar ninguém", fazendo questão de frisar que "todos são iguais na assistência". Ao serem investigados sobre a operacionalização do termo IGUAL, afirmaram a sua correspondência com o OTIMO.

Vale salientar que vários pacientes emitiram depoimentos escritos (bilhetes) acerca do bom desempenho dos alunos, os quais foram entregues aos professores e ao próprio aluno. Este mesmo desempenho chegou ao conhecimento da direção médica, por iniciativa pessoal de um paciente.

TABELA 5 - Reações dos pacientes assistidos pelos estudantes e de enfermagem

\begin{tabular}{l|r|r}
\hline ESPECIFICAÇÕES DAS REAÇÕES & F & \multicolumn{1}{|c}{$\%$} \\
\hline Tranqilidade & 36 & 87,80 \\
Segurança & 04 & 9,76 \\
Não sabe informar & 01 & 2,44 \\
\hline \multicolumn{1}{c|}{ TOTAL } & 41 & 100,00 \\
\hline
\end{tabular}

A tabela 6 caracteriza a opinião dos pacientes sobre os diversos aspectos da assistência prestada pelo estudante de enfermagem e revela que $35(85,36 \%)$ pacientes foram atendidos pelos estudantes em suas necessidades de higiene corporal, na organização de sua unidade, na administração dos seus medicamen. tos, no diálogo sobre seus problemas e nas orientações que recebiam dos educandos. Outros $(4-9,76 \%)$ disseram que o aluno se deteve mais na identificação e resolução dos seus problemas e $2(4,88 \%)$ se sentiram mais atendidos no que se refere às orientações que receberam dos estudantes. Se $35(85,35 \%)$ dos pacientes se sentiram atendidos nos vários aspectos 
da assistência que receberam do estudante de enfermagem, convém reforçar este aspecto citando o que CARVALHO \& CASTRO6 dizem: "a função de uma profissão se explica à medida que ela desenvolve suas atividades. Assim o que importa não é o que ela sabe, ensina ou delega; o que importa é o que ele faz, com autonomia no âmbito de suas funções... Por isso, a prática é que determina a posição do status do enfermeiro na sociedade".

TABELA 6 - Respostas dos pacientes sobre a especificação dos cuidados que recebiam dos estudantes de Enfermagem.

\begin{tabular}{l|c|c}
\hline ESPECIFICAÇÕES & F & $\%$ \\
\hline Cuidados higiênicos & - & - \\
Organização de sua Unidade & - & - \\
Administração de medicação & - & - \\
Conversa sobre seus problemas & 04 & 9,76 \\
Faz orientações & 02 & 4,88 \\
Atende a todos os ítens citados & 35 & 85,36 \\
\hline \multicolumn{1}{c|}{ TOTAL } & 41 & 100,00 \\
\hline
\end{tabular}

Ao serem inqueridos se desejavam fazer algum comentário e/ou sugestão acerca do estudante e/ou instituição, $11(26,82 \%)$ disseram que sim e 30 $(73,17 \%)$ se recusaram a qualquer comentário. Os $26,82 \%$ apresentaram os comentários que se seguem:

- "é válida a presença dos estudantes, eles são pessoas dedicadas"

- "gostaria que sempre tivesse estudantes na clínica porque elas atendem sempre na hora certa; nos fornecem força e elevam o padrão do serviço. $O$ atendimento é superior".

- "quero parabenizar minha estudante: ela é ótima".

- "gostaria que a minha estudante continuasse comigo".

- "nós soubemos que o diretor do hospital quer bloquear o estágio dos estudantes de enfermagem. Quero que a sra. saiba que estaremos dispostos a abrir um movimento contra essa atitude da diretoria indo inclusive ao jornal e à TV".

- "gostaria de sugerir que sempre tivessem estudantes pois melhoram a assistência. Se todos os hospitais tivessem estudantes seria uma beleza."

Às respostas evidenciaram o posicionamento dos pacientes sobre a qualidade da assistência que eles gostariam de receber, refletindo assim a consciência da comunidade que começa a defender os seus direitos.

E, reforçando o pensamento acima, DER DIARIA apud RHODUS ${ }^{14}$ afirma que "a existência de uma profissão é justificada a partir da identificação das necessidades de uma sociedade quanto aos seus serviços..." CARVALHO 5 reafirma o exposto quando diz que "a prática resume o significado de uma profissão na sociedade, porque nela se consubstancia a realização do compromisso social, o qual sendo obrigatório e coletivo, garante à profissão sua continuidade no tempo".

\section{CONCLUSÃO}

O estudo revela a opinião de 41 pacientes hospitalizados em uma instituição de atendimento generalizado da rede oficial do INAMPS, Recife, sobre o estudante de enfermagem quando cumpria o estagiário curricular da disciplina Introdução à Enfermagem 2 .

Ressalta-se no trabalho a relevância do IDA firmado entre as instituições de ensino e de assistência, o qual deve estar em constante interação levando assim benefícios para as instituições, para o cliente/ paciente $c$ para a comunidade. As responsabilidades que competem às instituições de ensino/assistência são expressadas de tal forma que os obstáculos aos estágios de alunos não devam existir. Tal fato não se observou na instituição onde se desenvolveu o estudo que mostrou relevante contradição entre as justificativas apresentadas pela direção e os resultados obtidos.

Pode-se concluir que:

- o paciente previdenciário aceita e até prefere a assistência prestada pelo estudante, fato este que foi comprovado pelos resultados, e revalidado pelas opiniões dos pacientes.

- o paciente identifica quando recebe assistência sistematizada e metodológica, fato evidenciado pela identificação do aluno na equipe de enfermagem. Este aspecto mostra que o aluno funciona como agente de mudança cujos benefícios refletem no próprio padrão de assistência da clínica.

- o estágio, sendo estruturado de forma sistematizada e com supervisão direta, fornece ao aluno subsídios para desenvolver suas atividades dentro de uma segurança tal que é percebida e assimilada por alguns pacientes como se tivessem sendo assistidos por um profissional e não por estudante.

- as sugestões emitidas pelos pacientes no final do questionário indicam que os estágios devem continuar não só como benefício para os previdenciários mas também para a própria instituição.

\section{SUGESTÕES}

A partir do que foi exposto, sugere-se:

\section{Às Escolas de Enfermagem que:}

- Estabeleçam convênios com as Instituições de Saúde, garantindo assim o campo de prática para que o aluno desenvolva suas atividades dentro de um clima favorável à sua aprendizagem.

- Através do convênio, seja firmado a implantação do Programa de Integração Docente/Assistencial, IDA, objetivando assistência mais fundamentada em princípios científicos, campos de prática mais estruturados e melhoria do serviço, beneficiando o doente, o aluno e a empresa.

- Estimulem os docentes a assumirem o IDA, para que a integração ensino/serviço seja consolidada e marcada como uma realidade.

\section{Às Instituições de Assistência que:}

- Redefinam o seu compromisso social, procurando contribuir com a elevação do nível de saúde da comunidade. 
- Acatem a permanência do aluno na empresa, baseando-se nos resultdos da pesquisa ora relatada.

\section{Aos Serviços de Enfermagem que:}

- Despertem para a necessidade de se estabelecer e se efetivar o intercâmbio interprofissional dentro da Instituição, levando a toda equipe multiprofissional o significado da profissão de Enfermagem.

- Estimulem o enfermeiro a participar de pesquisas conjuntas com outros profissionais da equipe de saúde, ocupando o espaço que lhe cabe dentro desta equipe.

- Lutem pela permanência do aluno na Instituição, mostrando que, através dele, o processo de conscientização sobre a assistência de enfermagem é levado às Instituições.

- Lutem pela implementação do IDA assegurando o caráter de educação permanente no serviço e garantindo a presença do aluno nos cenários da Instituição .

\section{Aos Enfermeiros que:}

- Procurem nortear suas atividades em função do paciente, de modo a que o aluno possa se mirar no seu modelo de enfermeiro assistencial e na sua postura profissional.

- Procurem, através da educação continuada, se capacitar para uma enfermagem científica.

- Realizem pesquisas no seu campo de trabalho e no exercício de suas funções.

- Estabelaçam o intercâmbio científico e o relacionamento interdependente com os docentes, somando esforços e abrindo espaços em prol da profissão, do doente e da sociedade.

- Participem da formação acadêmica do futuro profissional de Enfermagem, emitindo ensinamentos e responsabilizando-se pelo seu crescimento.

\section{Aos Estudantes que:}

- Marquem sua presença nas Instituções prestadoras de assistência, através do trabalho fundamentado na responsabilidade e nos princípios científicos.

- Integrem a equipe de saúde procurando estabelecer com seus membros um relacionamento interdependente.

- Dirijam suas ações para o paciente/famılia visando a humanização e a individualização da assistência.

- Solicitem a participação dos enfermeiros nos campos de prática, de modo que possam ser beneficiados com sua experiência.

- Estejam preparados para prestar informações sobre o estado de saúde dos pacientes sob sua responsabilidade, garantindo o processo de comunicação horizontal na Instituição e na equipe.

LINS, L. C. S. \& SÁ, M. P. C. de. Evaluation the nursing care gived by the nursing students in an INAMPS general hospital in the Recife city - patients opinion. Rev. Bras. Enf., Brasília, 39(2/3): 38-45, Apr./Sept., 1986.

\section{REFERẼNCIAS BIBLIOGRÁFICAS}

1. ALMEIDA, M. C. P. A construção do saber na enfermagem: evolução histórica. In: SEMINÁRIO NACIONAL DE PESQUISA EM ENFERMAGEM, 3., Florianópolis, 1 a 6 abril de 1984. Anais. . . Florianópolis, Editora da UFSC, 1984. p.58-77.

2. ARAÚJO, E. C. et alii. Assistência de enfermagem pela problemática do INAMPS. In: CONGRESSO BRASILEIRO DE ENFERMAGEM, 32., Brasília, 1 a 7 de junho de 1980. Anais. . Brasília, ABEn, 1980. p. 33-46.

3. BEZERRA, G. L. Portaria normativa no 22/81 cria programa de Integração Docente Assistencial. Bol. Of. Univ. Fed. Pernambuco, Recife, 16 (21): 939-41, nov. 1981.

4. BRASIL. Ministério da Educação e Cultura. Secretaria de Ensino Superior. Programa de Integração Docente Assistencial - IDA. Brasília, 1981. (Cadernos de Ciências da Saúde, 3).

5. CARVALHO, V. A relação de ajuda e a totalidade da política da enfermagem. In: CONGRESSO BRASILEIRO DE ENFERMAGEM, 32., Brasília, 1 a 7 de junho de 1980. Anais. . Brasília, ABEn, 1980. p.65-72.

6. \& \&ASTRO, I. B. Reflexões sobre a prática da enfermagem. In: CONGRESSO BRASILEIRO DE ENFERMAGEM, 31., Fortaleza, 5 a 11 de agosto de 1979. Anais. . . Fortaleza. ABEn, 1979. p.51-9.

7. CIETTO, L. \& PEREIRA, D. M. D. S. Integração da assistência e do ensino de enfermagem: considerações sobre aspectos organizacionais e administrativos. Rev. Bras. Enf., Brasília, 34 (1):41-7, jan./mar. 1981 .

8. FARAON, V. M. C. A(o) enfermeira(o) e a enfermagem. In: CONGRESSO BRASILEIRO DE ENFERMAGEM, 33., Manaus, 2 a 7 de agosto de 1981. Anais. . . Manaus, ABEn, 1981. p.37-41.

9. FERNANDES, J. D. Contribuição da equipe multiprofissional nas ações de saúde: mito ou felicidade? Rev. Bras. Enf., Brasília, 34 (2): 175-81, abr./ jun. 1981.

10. FERNANDES, L. L. \& LEITE, N. L. Integração do ensino com a assistência na enfermagem - uma prioridade para o campo clínico. Rev. Bras. Enf., Brasília, 34 (2): 164-74, abr./jun. 1981.

11. OGUISSO, T. \& SCHMIDT, M. J. Sistema de prestação de serviços de saúde e sua repercussão na enfermagem. In: CONGRESSO BRASILEIRO DE ENFERMAGEM, 31., Fortaleza, 5 a 11 de agosto de 1979. Anais. . . Fortaleza, ABEn, 1979. p. 39-49.

12. OLIVEIRA, M. I. R. O enfermeiro e a enfermagem. In: CONGRESSO BRASILEIRO DE ENFERMAGEM, 33., Manaus, 2 a 7 de agosto de 1981. Anais. . . Manaus, ABEn, 1981.p. 19-31.

13. Paula, N. S. A formação do enfermeiro. Rev. Paul. Enf., São Paulo, 4 (1): 37-9, jan./mar. 1984.

14. RHODUS, C. C. Preparo e aperfeiçoamento de recursos humanos para a enfermagem. In: CONGRESSO BRASILEIRO DE ENFERMAGEM. 31., Fortaleza, 5 a 11 de agosto de 1979. Anais. . . Fortaleza, ABEn, 1979. p.93-9.

15. VIEIRA, T. T. et alii. A competência continuada e a assistência de enfermagem. In: CONGRESSO BRASILEIRO DE ENFERMAGEM, 32., Brasília, 1 a 7 de junho de 1980. Anais. . . Brasília, ABEn, 1980. p. 47-56. 